NASA Technical Memorandum 89890

AIAA-87-1316

\title{
Numerical Simulations of Unsteady, Viscous, Transonic Flow Over Isolated and Cascaded Airfoils Using a Deforming Grid
}

\author{
(NASA-TM-89890) NUHEEJEATERLIATICNS OF N87-24435 \\ UNSTEADY, VISCCLS, TRALSONIC HIOW OVEH \\ ISCLATED AND CASCALED AIRFCILS CSING A \\ CEFCNUING GRID (NASA) $16 \mathrm{f}$ Avail: NTIS Jnclas \\ EC $\triangle$ C2/DF A01 CSCL $01 A$ G3/02 $00 E 3769$
}

Dennis L. Huff

Lewis Research Center

Cleveland, Ohio

Prepared for the

19th Fluid Dynamics, Plasma Dynamics and Lasers Conference sponsored by the American Institute of Aeronautics and Astronautics Honolulu, Hawaii, June 8-10, 1987 
NUMERICAL SIMULATIONS OF UNSTEADY, VISCOUS, TRANSONIC FLOW OVER ISOLATED

AND CASCADED AIRFOILS USING A DEFORMING GRID

\author{
Dennis L. Huff* \\ National Aeronautics and Space Administration \\ Lewis Research Center \\ Cleveland, Ohio 44135
}

\title{
SUMMARY
}

A compressible, unsteady, full Navier-Stokes, finite difference code has been developed for modeling transonic flow through two-dimensional, oscillating cascades. The procedure introduces a deforming grid technique to capture the motion of the airfoils. Results using a deforming grid are presented for both isolated and cascaded airfoils. The load histories and unsteady pressure distributions are predicted for the NACA $64 A 010$ isolated airfoll and compared with existing experimental data. Results show that the deforming grid technique can $\approx$ be used to successfully predict the unsteady flow properties around an oscillating airfoil. The deforming grid technique has been extended for modeling unsteady flow in a cascade. The use of a deforming grid simplifies the specification of boundary conditions. Unsteady flow solutions similar to the isolated airfoil predictions are found for a NACA 0012 cascade with zero interblade phase angle and zero stagger. Experimental data for these cases are not avallable for code validation, but computational results are presented to show sample predictions from the code. Applications of the code to typical turbomachinery flow conditions will be presented in future work.

\section{INTRODUCTION}

The analysis of flow around advanced turboprop airfoil sections requires methods capable of modeling unsteady, transonic flow. As the number of blades increase, the cascade effects are expected to become more significant. To date, most of the flow codes that model unsteady, transonic cascades are linearized potential solvers. While these codes are fast and more practical for load predictions, they are not expected to model the true physics of the flow. There is no experimental data avallable for propfan sections that can determine the extent of the unsteady effects. In an attempt to bridge the gap in understanding and modeling unsteady, transonic flow through cascades, a compressible Navier-Stokes code has been developed for such applications. The present code introduces a deforming grid technique to capture the blade motion in the cascade. The use of a deforming grid is convenient for treatment of the outer boundary conditions since the outer boundary can be fixed in space, while the inner boundary moves with the blade motion. This is desirable for oscillating airfoils in a cascade since the outer boundary position must be known. Sample calculations are presented for both isolated and cascaded airfoils and compared to experiment when possible.

\footnotetext{
*Member, AIAA.
} 


\section{NOMENCLATURE}

C sonic velocity

$\mathrm{Cl}$ lift coefficient

CM moment coefficient about the leading edge

$C P$ pressure coefficient

$C_{\infty}$ free-stream speed of sound

c blade chord length

e total energy of the fluid per unit volume

GCL Geometric Conservation Law

g gap-to-chord ratio

J Jacobian of transformation

$k$ reduced frequency based on semichord, $\omega c / 2 U_{\infty}$

M Mach number

Re Reynolds number based on chord

$\mathrm{R}^{-} \quad$ upstream-running Riemann invariant

$s$ arclength of a grid line in the $n$-direction

$t$ time normalized by $c / C_{\infty}$

$U_{\infty}$ free-stream velocity

$u, v$ Cartesian velocities normalized by $C_{\infty}$

$v$ total velocity

w weighting function for grid deformation

$x, y$ Cartesian coordinates normalized by chord length

a angle of attack in degrees

$\alpha_{m}$ mean angle of attack

a) amplitude of pitching

$\gamma$ ratio of specific heats

$n$ normal direction of transformed coordinate system

$\xi$ chordwise direction of transformed coordinate system 


\author{
p density \\ T time variable \\ $\boldsymbol{\omega}$ \\ airfoil oscillation frequency
}

\title{
GOVERNING EQUATIONS
}

The code is an extension of the isolated airfoll code developed by Sankar and Tang (ref. 1). This code solves the two-dimensional, unsteady, Reynoldsaveraged, compressible Navier-Stokes equations on a body-fitted moving coordinate system in strong conservation form using an ADI procedure. The cascade code uses the same ADI procedure to solve for the interior of the computational domain. The outer boundary conditions are modified to model cascaded airfoils and are described later in this paper. A complete description of the formulation for isolated airfoils is included in reference 1, and only a brief outline is given here.

The two-dimensional, unsteady Navier-Stokes equations can be written as:

$$
\hat{q}_{\tau}+\hat{F}_{\xi}+\hat{G}_{\eta}=\hat{R}_{\xi}+\hat{S}_{\eta}
$$

where

$$
\hat{q}=J^{-1}\{\rho, \rho U, \rho v, e\}
$$

and $\rho$ is the fluid density; $u$ and $v$ are the Cartesian components of the fluid velocity; $e$ is the total energy per unit volume. The body-fitted $(\xi, n, \tau)$ coordinate system is related to the Cartesian coordinates using the following transformation:

$$
\begin{aligned}
& \xi=\xi(x, y, t) \\
& n=n(x, y, t) \\
& \tau=t
\end{aligned}
$$

The Jacobian of the transformation is given by:

$$
J=\xi_{x} n_{y}-n_{x} \xi_{y}=\frac{1}{\left(x_{\xi} y_{n}-x_{n} y_{\xi}\right)}
$$

and the metrics of the transformation are given by:

$$
\begin{aligned}
& \xi_{x}=J y_{n} \\
& \xi_{y}=-J x_{n} \\
& n_{x}=-J y_{\xi} \\
& n_{y}=J x_{\xi}
\end{aligned}
$$


Standard central differences were used to compute $x_{\xi}, y_{\xi}, x_{n}$ and $y_{n}$ which were then used to calculate the metrics.

The $F$ and $G$ terms in equation (1) are the inviscid flux terms in the $\xi$ and $n$-directions, respectively. The $\hat{k}$ and $\hat{s}$ quantities are the corresponding viscous stress terms. The viscous terms can be omitted to give solutions for the Euler equations. The Beam-Warming, block ADI algorithm is used to solve the governing equations. The viscous terms are treated explicitiy to reduce the computational time. Artificial dissipation is added to help the stability and follows an improved method used by Sankar and Tang (ref. 1) to reduce excessive smearing of embedded vortices. The discretized form of equation (1) becomes:

$$
\frac{\Delta \hat{q}_{i j}^{n+1}}{\Delta \tau}+\delta_{\xi} \hat{F}_{i j}^{n+1}+\delta_{n} \hat{G}_{i j}^{n+1}=\delta_{\xi} \hat{R}^{n}+\delta_{\eta} \hat{S}^{n}-\varepsilon_{E} D_{i j}^{n}
$$

where

$$
\Delta \hat{q}_{i j}^{n+1}=\hat{q}_{i j}^{n+1}-\hat{q}_{i j}^{n}
$$

$D_{1 j}$ is the dissipation term, $\varepsilon_{E}$ controls the amount of dissipation, $\Delta \tau$ is the time step, and $\delta_{\xi}$ and $\delta_{n}$ are standard central difference operators. The $\hat{F}$ and $\hat{G}$ terms are nonlinear and are calculated using a Taylor series about the " $n$ " time level. The solution is second-order accurate in space and first-order accurate in time. The Baldwin-Lomax, two-layer algebraic model (ref. 2) is used to evaluate the eddy viscosity and the entire flow field is assumed to be turbulent.

\section{GRID}

The flow solver uses a $C$-grid generated from Sorenson's (ref. 3) GRAPE (GRids about Airfolls using Poisson's Equations) code. Several test cases have been presented by Huff. Wu and Sankar (ref. 4) using the present code and C-grids from the GRAPE code for isolated airfolls. For cascaded airfolls, the grids are generated by specifying an outer boundary shape for the C-grid and forcing periodicity on the upper and lower boundaries, as shown in figure 1.

Solutions for pitching or plunging isolated airfoils are found by moving the entire grid as a rigid body. This procedure is valid when the outer boundary remains in the free stream. For cascade analysis, the outer boundary position must be known to apply the appropriate boundary conditions. A deforming grid technique is used in this analysis to locate the position of the grid as a function of time. The inner boundary moves with the airfoil, while the outer boundary remains fixed in space. The grid lines connecting the inner and outer boundaries of the C-grid are allowed to deform. This avoids difficult interpolation of the flow properties along the periodic boundaries. The amount of deformation is a function of the distance away from the surface of the airfoil. Define a weighting function, $w$, to be:

$$
W(\xi, n)=\left|\frac{s(\xi, n)}{s\left(\xi, \eta_{\max }\right)}-1\right|
$$


where $s$ the arclength of a grid line from the airfoll surface $(n=1)$ to some grid point along $\xi=$ constant, and $n_{\max }=$ the outer boundary grid line. From equation $(6)$, we see that $w=1$ when $s(\xi, \eta)=0$ and $w=0$ when $s(\xi, n)=s\left(\xi, n_{\max }\right)$. This function is used to find the amount of grid deformation for each new time step:

$$
\begin{aligned}
& x_{i j}^{n+1}=x_{i j}^{n}+w_{i j}\left(\Delta x_{i j}\right)_{r i g} \\
& y_{i j}^{n+1}=y_{i j}^{n}+w_{i j}\left(\Delta y_{i j}\right)_{r i g}
\end{aligned}
$$

where $\left(\Delta x_{i j}\right)$ rig and $\left(\Delta y_{i j}\right) r i g$ are the spatial differences if the entire grid were rotated as a rigid body. Finally, the amount of deformation of the grid over one time step can be defined as:

$$
\begin{aligned}
& \left(\Delta x_{i j}\right)_{\text {def }}=w_{i j}\left(\Delta x_{1 j}\right)_{r i g} \\
& \left(\Delta y_{i j}\right)_{\text {def }}=w_{i j}\left(\Delta y_{1 j}\right)_{r i g}
\end{aligned}
$$

The total velocity of the flow at any point on the grid is equal to the grid velocity plus the velocity of the flow with respect to the grid. At the outer boundary, the grid is fixed in space and the grid velocity is zero. The grid velocity changes with the amount of deformation, giving the following Cartesian grid velocities:

$$
\begin{aligned}
& \left(x_{1 j}\right)_{\tau}=\frac{d x}{d \tau}=\frac{\left(\Delta x_{1 j}\right)_{\text {def }}}{\Delta \tau} \\
& \left(y_{1 j}\right)_{\tau}=\frac{d y}{d \tau}=\frac{\left(\Delta y_{1 j}\right)_{\text {def }}}{\Delta \tau}
\end{aligned}
$$

With the grid velocities known, the flow solver can predict the unsteady flow properties at any desired time. However, as noted by Thomas and Lombard (ref. 5) and Shamroth and Gibeling (ref. 6), a moving grid requires careful treatment of the metric data to account for the time variation of the Jacobian of transformation. The Geometric Conservation Law (GCL) was introduced by Thomas and Lombard (ref. 5) as a way to maintain global conservation of a moving grid when transforming from a body-fitted coordinate system to the computational plane. A grid that remains fixed in space does not need to account for the GCL since the time-dependent terms of the mapping are zero. When the grid deforms, the change in the Jacobian of transformation from the previous time level must be calculated using the GCL. In the present study, the $G C L$ is both included and excluded from the calculations to investigate its importance for the deforming grids.

\section{BOUNDARY CONDITIONS}

In order to properly model flow through a cascade, the outer boundary conditions must capture the physics of the flow field. The technique used here is similar to the approach used by Chima (ref. 7 ). The solution models a single blade and assumes periodic boundaries along the upper and lower grid 
lines. This will be true for cascades with zero interblade phase angles. Based on Shamroth, McDonald and Briley's (ref. 8) experience with modeling cascades, the metric data is also forced to be continuous along the perfodic boundaries.

The inlet conditions are assumed to be at free stream total pressure and temperature. The desired flow angle is also a necessary input to completely specify the inlet boundary conditions. Similiar to Jameson (ref. 9) the upstream-running Riemann invariant based on total velocity is calculated and extrapolated from the interior to give a nonreflecting boundary condition:

$$
R^{-}=\left[V-\frac{2 C}{r-1}\right]
$$

where $V=$ the total velocity

$C=$ the sonic velocity

Although this boundary condition is only valid for steady flows, it is used here as an approximation for the full unsteady boundary condition by assuming that the unsteady terms are negligible. In theory, the nonreflecting boundary condition allows the upstream boundary to be closer to the blade without decreasing the convergence rate. With $R^{-}$known at the inlet, the total velocity and velocity components are known. The static pressure and density are found assuming isentropic flow, and the energy is found from the relation:

$$
e=\frac{1}{y-1} p+\frac{1}{2} \rho\left(u^{2}+v^{2}\right)
$$

This gives all inlet conditions specified in terms of the conservation variables used in equation (2).

The exit boundary conditions extrapolate $\rho$, $\rho u$, and $\rho v$ from the interior and specify free stream static pressure to calculate energy. An exit Riemann invariant cannot be specified since it would vary across a viscous wake.

The remainder of the boundary conditions are identical to those used for isolated airfoils in reference 1. This includes solid wall boundaries on the airfoll surface and averaging the flow conditions across the slit aft of the airfoil.

\section{RESULTS AND DISCUSSION}

Results from the sample runs are divided into two categories: (1) a pitching, isolated airfoil to test the deforming grid technique, (2) steady and unsteady predictions for a cascade with zero interblade phase angles and zero stagger. The airfoils used in this investigation are thicker than typical sections found on the propfan. They have been chosen for code validation since experimental data for thinner sections does not exist. Preliminary calculations have been done for the NACA 16 series airfoils and will be presented in a future paper. 


\section{NACA 64A010 Isolated Airfoil}

The NACA 64A010 airfoll has been chosen for testing the deforming grid concept because of the extensive data presented by Davis and Malcom in reference 10. This data was taken in the 11 by 11 foot transonic wind tunnel at the NASA Ames Research Center. A test case commonly used by other researchers is: $M=0.80, \operatorname{Re}=12.56$ miliion, $\alpha_{m}=-0.21^{\circ}, \alpha_{1}= \pm 1.02^{\circ}$, and $k=0.202$ (reduced frequency based on semichord). This case is used in the present study for comparisons with code predictions.

Figure 2 shows a fully deformed grid superimposed on a simplified C-grid for the NACA $64 A 010$ airfoti. The actual grid used in the predictions is a 157 by $58 \mathrm{C}$-grid, with 97 points wrapped around the airfoil and 60 points in the wake. The grid is initially generated at the mean angle and then allowed to deform so that the maximum deformation occurs at the maximum and minimum pitching angles. The plot shows two grids: (1) the initial, rigid grid generated at $\alpha=\alpha_{m}$ (solid line), and (2) the fully deformed grid at the maximum pitching angle (dashed line). The grid will also deform in the opposite direction to the minimum pitching angle. Notice in figure 2 how the outer boundary remains fixed, while the inner boundary moves with the motion of the airfoll surface. The grid connecting the inner and outer boundaries deforms, as fllustrated by the space between the solid and dashed grid lines.

An average outer boundary distance of ten chord lengths was chosen based on the results of a grid parameter study in reference 4 using the NACA 0012 airfoil. The distance of the first grid line off the surface of the airfoil is 0.00005 chords, which should be adequate for the selected Reynolds number.

Three separate calculations were studied for this test case. The first calculation rotates the grid as a rigid body that follows the airfoil motion. The second calculation (deforming, with GCL) uses a deforming grid and includes the Geometric Conservation Law in the calculation of the Jacobian. In order to determine the importance of the GCL for deforming grids, the third calculation (deforming, without GCL) uses a deforming grid without conserving the time dependent terms in the Jacobian calculation. All three calculations were performed using five cycles of pitching and were found to be periodic in the fourth cycles. The mean angle of attack used in the predictions was adjusted to $\alpha_{m}=-0.19^{\circ}$ instead of $\alpha_{m}=-0.21^{\circ}$ used in the experiment. This was done to match the mean lift coefficient. (Since the object of this analysis is to obtain load information, matching the lift and moment coefficients is more useful than only matching the pressures on the surface with the shock wave. The results may still need to be corrected for wind tunnel wall interference.)

The lift and moment predictions from all three cases are shown in figures 3 and 4, respectively. The coefficients from a Fourier transform on the fourth cycle are shown in table I, with the results plotted in figures 5 and 6 for comparison with experiment. The steady-state pressure distributions for the adjusted mean angle are compared with experimental data in figure 7 . The real and imaginary components of pressure normalized by the amplitude of oscillation are plotted in figures 8 and 9 , respectively.

The results are in reasonably good agreement with experiment and are comparable to the results reported by Chyu and Davis (ref. 13)., who also used a Navier-Stokes solver. Furthermore, the predictions using a rigid grid are 
very close to the predictions using a deforming grid, which validates the use of a deforming grid for unsteady analysis. There are only minor differences between the deforming grid calculations when the GCL is included and excluded. The time step used for these calculations was small enough that the error from excluding the GCL is very small. It is expected that including the GCL in the formulation will be more important for grids with higher deformation and larger time steps. Also, the deforming grid technique is expected to lose accuracy as the pitching angle becomes large since the orthogonality and smoothness of the grid is not as good as the numerical grid generated at the mean angle. One way to get around this is to generate another grid after a few degrees of pitching and then continue the deformation technique.

\section{NACA 0012 Cascade}

The deforming grid technique can be extended to predict the flow field for an oscillating cascade. No experimental data is avallable to validate such calculations. The solutions presented here will be a first attempt to capture the flow behavior for oscillating cascades using a full Navier-Stokes solver. The first case to be considered is a NACA 0012 cascade with $g=3.6, M=0.80$, $\operatorname{Re}=3.45 \mathrm{million}$, and $\alpha_{m}=0.0^{\circ}$. The steady-state solution for pressure distribution is shown in figure 10, along with predictions from other flow solvers in references 11 and 12. Caughey and Jameson (ref. 11) show results from a transonic potential solver and present solutions using a 80 by 12 grid and a 160 by 24 grid. Farrell and Adamczyk (ref. 12) also use a transonic full potential solver for the same case using a 98 by 25 grid. The shock strength and location predictions from the present analys is are in good agreement with the other solutions. The shock is smeared, but can be made sharper by adding more grid lines in the $\xi$-direction.

Two cases for a gap-to-chord ratio of one are considered next, with $M=0.593$ and $M=0.660$ ( $R e=3.21$ million, $\left.\alpha_{m}=0.0^{\circ}\right)$. These cases represent predictions for the cascade with both subsonic and transonic flow. A 157 by 40 grid was used for these calculations and is shown in figure 1 . The unsteady load histories for the airfolls with $\alpha_{1}= \pm 2.0^{\circ}$ about the mean angle, $M=0.593$, and $k=0.20$ are shown in figures 11 and 12 . The solutions reach a periodic solution by the third cycle. Results for $M=0.660$ are not plotted since they look very similar. The Fourier Transform coefficients for the first harmonics on the fourth cycle of pitching are included in table 1 . Predictions for the mean, real and imaginary components of pressure are presented in figures 13 to 15 , respectively. The mean pressure distributions show a weak shock developing when $M=0.660$. The imaginary components of pressure are relatively small for both cases.

A11 runs were done on the CRAY-XMP computer at NASA Lewis. The steadystate solutions required about 2000 iterations for convergence and took $3.8 \times 10^{-5} \mathrm{sec}$ per iteration per grid point. The unsteady solutions for the NACA $64 A 010$ airfoil used 7854 iterations to complete one cycle of pitching using a time step size of 0.0025 . Both of the unsteady runs for the NACA 0012 cascade required a time step size of 0.004 and took 6545 iterations per cycle for $M=0.593$ and 5861 iterations per cycle for $M=0.660$. The unsteady calculations use $4.3 \times 10^{-5} \mathrm{sec}$ per iteration per grid point. 


\section{CONCLUSIONS}

A compressible, unsteady, full Navier-Stokes code has been developed for the analysis of oscillating cascades. The present study introduces a deforming grid method to model the airfoll motion and boundary conditions. Results from the deforming grid computations are in good agreement with isolated airfoll predictions that use a standard rigid grid. Including the Geometric Conservation Law in the Jacobian of transformation has little effect on the solutions investigated in this study. The deforming grid technique has been extended to model cascaded airfolls and is ready for comparison with experiment. To this author's knowledge, this is the first time that a deforming grid has been included in a Navier-Stokes code for oscillating cascade analysis. In addition to the valuable aid to the analysis of unsteady flow through cascades, this method can be extended to aeroelastic modeling of nonrigid airfoils.

\section{ACKNOWLEDGEMENTS}

The author wishes to thank Dr. Rodrick V. Chima of the NASA Lewis Research Center, and Or. L.N. Sankar of the Georgia Institute of Technology for their helpful suggestions and guidance of this work.

\section{REFERENCES}

1. Sankar, N.L. and Tang, W., "Numerical Solution of Unsteady Viscous Flow Past Rotor Sections," AIAA Paper 85-0129, Jan. 1985.

2. Baldwin, B. and Lomax, H., "Thin-Layer Approximation and Algebraic Model For Separated Turbulent Flows," AIAA Paper 78-257, Jan. 1978.

3. Sorenson, R.L., "A Computer Program to Generate Two-Dimensional Grids About Airfoils and Other Shapes by the Use of Posson's Equation," NASA TM-81198, 1980.

4. Huff, D.L., Wu, J.C. and Sankar, L.N., "Analysis of Viscous Transonic Flow Over Airfoll Sections," AIAA Paper 87-0420, Jan. 1987.

5. Thomas, P.D. and Lombard, C.K., "The Geometric Conservation Law - A Link Between Finite-Difference and Finite-Volume Methods of Flow Computation on Moving Grids," AIAA Paper 78-1208, July 1978.

6. Shamroth, S.J. and Gibeling, H.J., "The Prediction of the Turbulent Flowfield About an Isolated Airfoil," AIAA Paper 79-1543, July 1979.

7. Chima, R.V., "Inviscid and Viscous Flows in Cascades with an Explicit Multiple-Grid Algorithm," AIAA Journal, Vol. 23, No. 10, Oct. 1985, pp. 1556-1563.

8. Shamroth, S.J., McDonald, H., and Briley, W.R., "Application of a Navier-Stokes Analysis to Transonic Cascade Flow Fields," ASME Paper 82-GT-235, Apr. 1982. 
9. Jameson, A. and Baker, T.J., "Solution of the Euler Equations for Complex Configuration," AIAA Paper 83-1929, July 1983.

10. Davis, S.S. and Malcolm, G. N., "Experimental Unsteady Aerodynamics of Conventional and Supercritical Airfoils," NASA TM-81221, 1980.

11. Caughey, D.A. and Jameson, A., "Numerical Calculation of Transonic Potential Flow About Wing-Fuselage Combinations," AIAA Paper 77-677, June 1977.

12. Farre11, C. and Adamczyk, J., "Full Potential Solution of Transonic Quasi-Three-Dimensional Flow Through a Cascade Using Artificial

Compressiblity," Journal of Engineering for Power, Vol. 104, No. 1, Jan. 1982, pp. 143-153.

13. Chyu, W.J. and Davis, S.S., "Numerical Studies of Unsteady Transonic Flow Over an Oscillating Airfoil," Transonic Unsteady Aerodynamics and its Aeroelastic Applications, AGARD CP-374, AGARD, Paris, France, 1984, pp. 3-1 to 3-22. (ATso, NASA TM-86011).

TABLE I. - FOURIER COEFFICIENTS FOR LIFT AND MOMENT

TIME HISTORIES (FIRST HARMONICS)

\begin{tabular}{|c|c|c|c|}
\hline Case & $a_{0}$ & $a_{1}$ & $b_{1}$ \\
\hline \multicolumn{4}{|c|}{$c_{L}=a_{0}+a_{1} \cos (\omega \tau)+b_{1} \sin (\omega \tau)$} \\
\hline $\begin{array}{l}\text { NACA } 64 A 010 \\
\text { Rigid grid } \\
\text { Deforming grid, with GCL } \\
\text { Deforming grid, without GCL } \\
\text { Experiment (ref. } 6 \text { ) } \\
\text { NACA 0012 } \\
\text { Cascade, M=0.593 } \\
\text { Cascade, } M=0.660\end{array}$ & $\begin{array}{r}-0.0283 \\
-.0283 \\
-.0284 \\
-.0290 \\
.0004 \\
.0006\end{array}$ & $\begin{array}{r}0.0995 \\
.0972 \\
.0969 \\
.0862 \\
.0708 \\
.0717\end{array}$ & $\begin{array}{r}0.0242 \\
.0254 \\
.0255 \\
.0444 \\
-.0323 \\
-.0338\end{array}$ \\
\hline \multicolumn{4}{|c|}{$C_{M}=a_{0}+a_{1} \cos (\omega \tau)+b_{1} \sin (\omega \tau)$} \\
\hline $\begin{array}{l}\text { NACA } 64 A 010 \\
\text { Rigid grid } \\
\text { Deforming grid, with GCL } \\
\text { Deforming grid, without GCL } \\
\text { Experiment (ref. } 6) \\
\text { NACA } 0012\end{array}$ & $\begin{array}{r}0.0092 \\
.0092 \\
.0092 \\
.0040\end{array}$ & $\begin{array}{r}-0.0352 \\
-.0344 \\
-.0343 \\
-.0249\end{array}$ & $\begin{array}{r}0.0015 \\
.0009 \\
.0008 \\
.0004\end{array}$ \\
\hline $\begin{array}{l}\text { Cascade, } M=0.593 \\
\text { Cascade, } M=0.660\end{array}$ & $\begin{array}{l}.0004 \\
.0004\end{array}$ & $\begin{array}{l}-.0069 \\
-.0019\end{array}$ & $\begin{array}{l}.0136 \\
.0146\end{array}$ \\
\hline
\end{tabular}




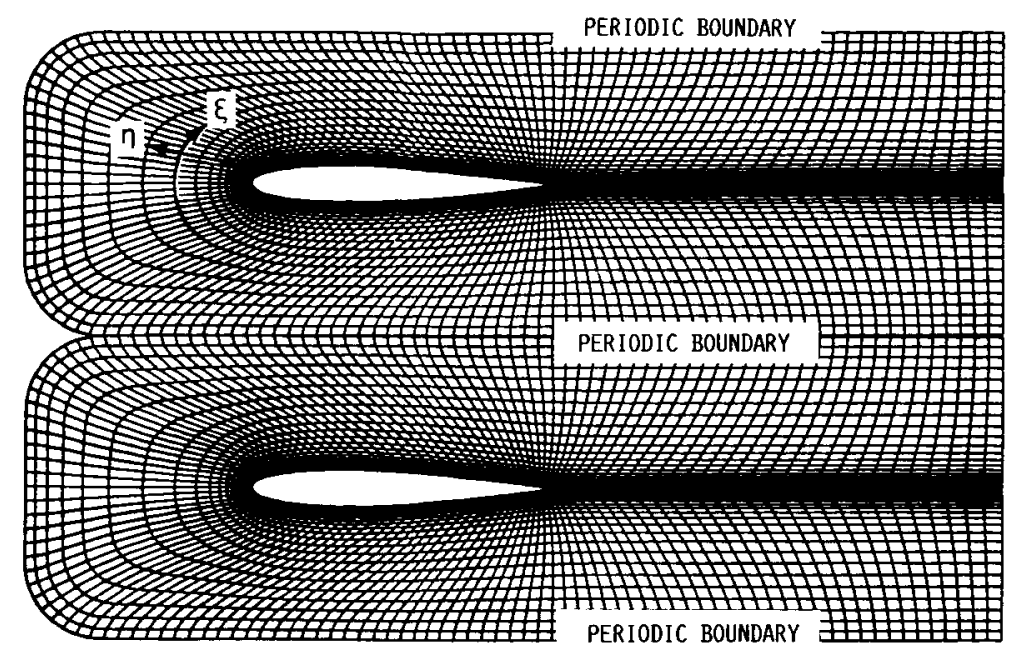

FIGURE 1. - GRID FOR THE NACA 0012 CASCADE.

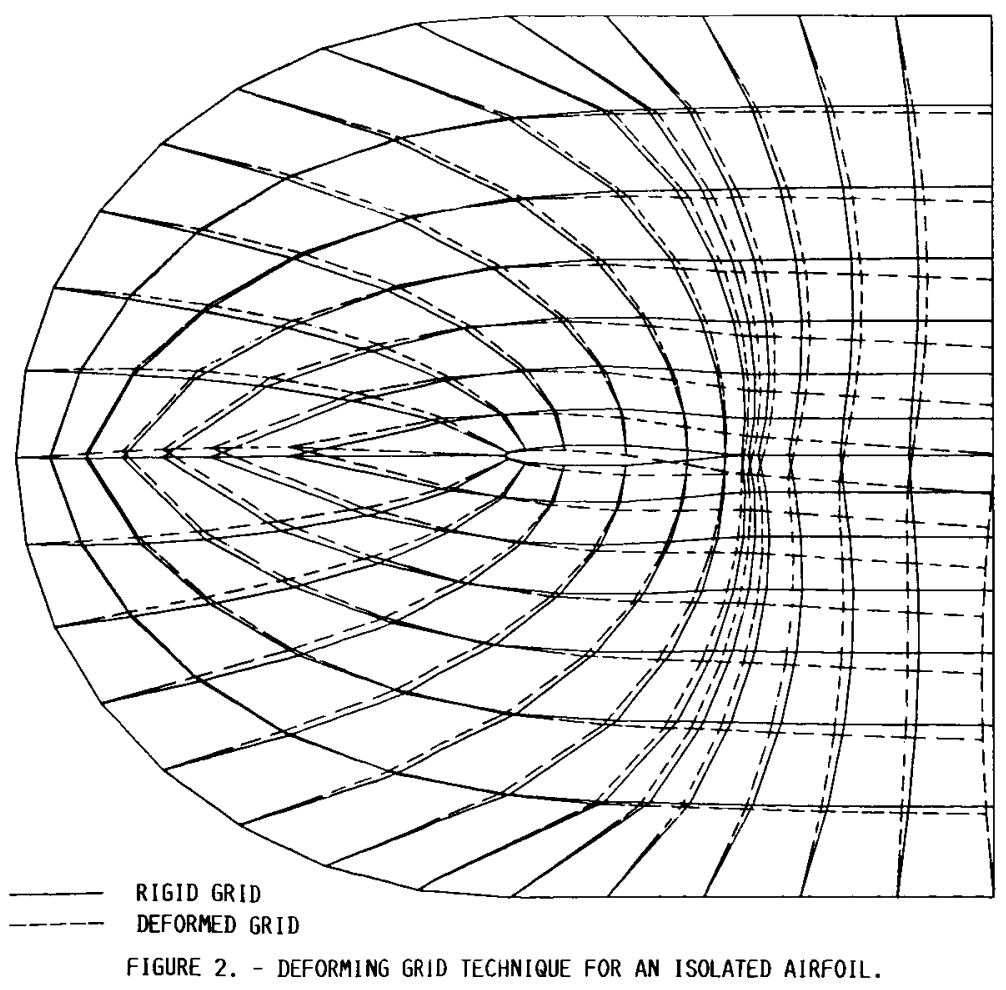




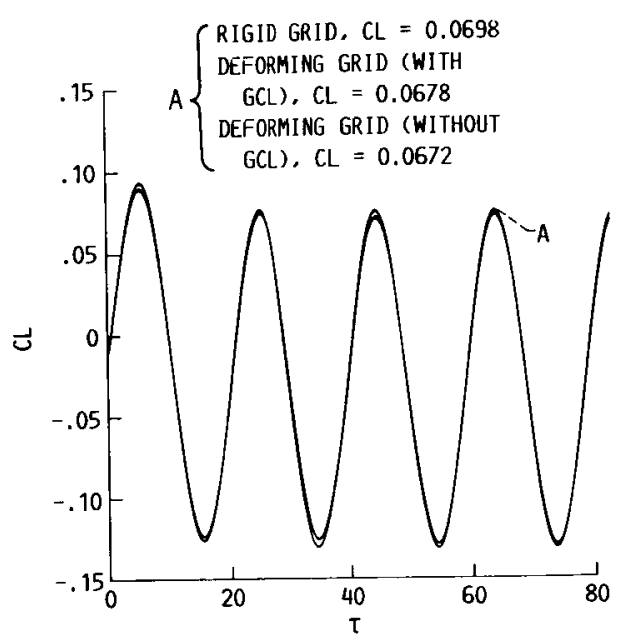

FIGURE 3. - CL VERSUS TIME. NACA $64 A 010$ AIRFOIL; $M=0.80 ; a_{m}=-0.19 ; a_{1}=$ $\pm 1.02 ; k=0.202 ; \operatorname{Re}=12.56 \times 10^{6}$.

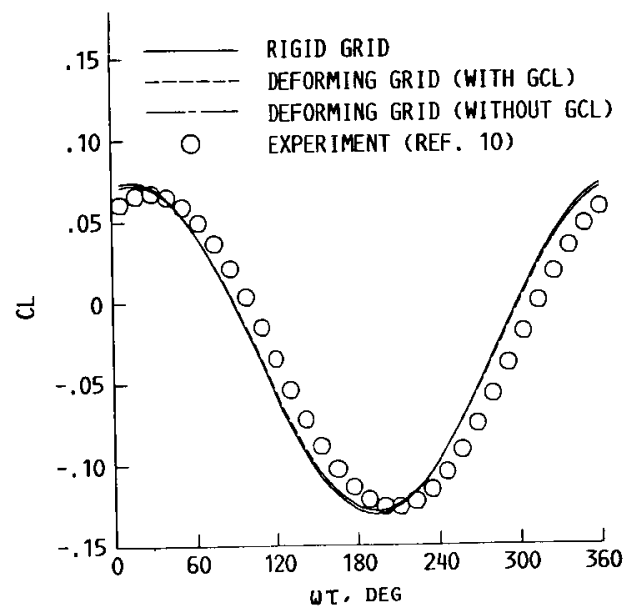

FIGURE 5. - FIRST HARMONICS OF FOURIER TRANSFORM FOR LIFT COEFFICIENT ON THE FOURTH CYCLE. NACA G4A010 AIRFOIL: $M=0.80 ; a_{m}=-0.19 ; a_{1}=$ $\pm 1.02 ; k=0.202: \operatorname{Re}=12.56 \times 10^{6}$.

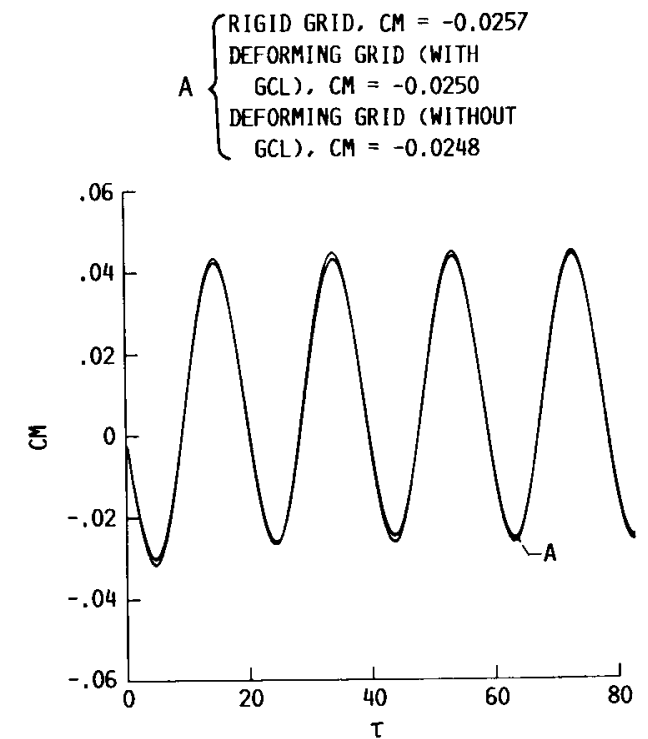

FIGURE 4. - CM VERSUS TIME, NACA G4A010 AIRFOIL; $M=0.80: a_{m}=-0.19: a_{1}=$ $\pm 1.02: k=0.202 ; \operatorname{Re}=12.56 \times 10^{6}$.

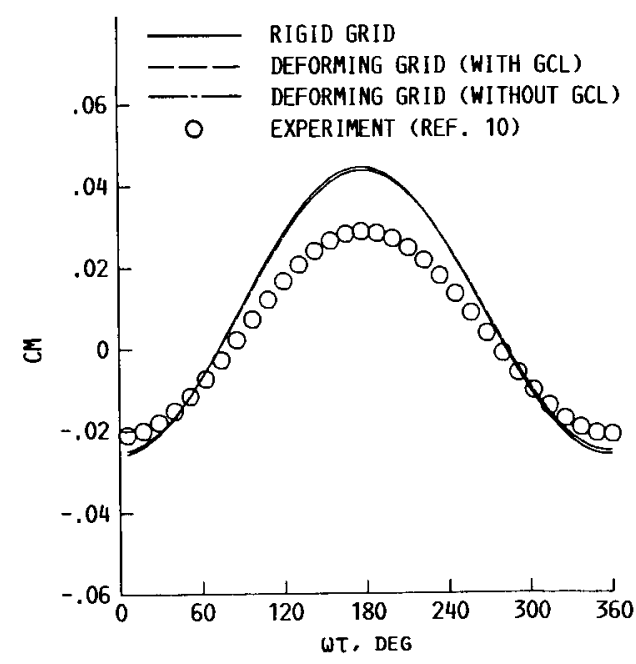

FIGURE 6. - FIRST HARMONICS OF FOURIER TRANSFORM FOR MOMENT COEFFICIENT ON THE FOURTH CYCLE. NACA 64A010 AIRFOIL: $M=0.80: a_{m}=-0.19 ; a_{1}=$ $\pm 1.02 ; k=0.202 ; \operatorname{Re}=12.56 \times 10^{6}$. 


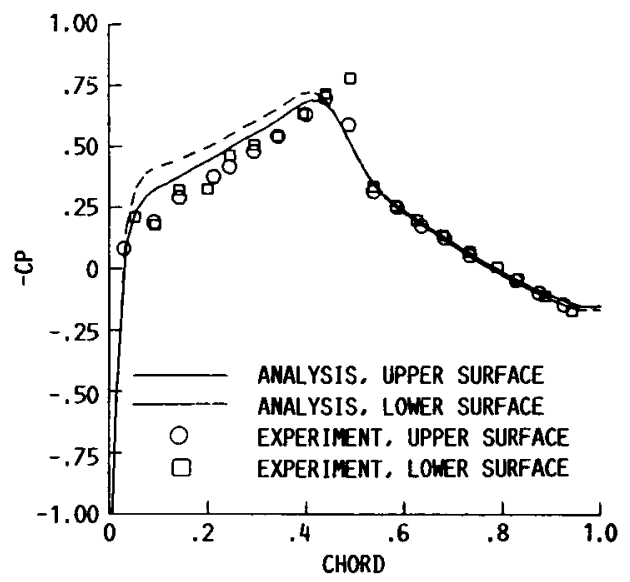

FIGURE 7. - MEAN PRESSURE DISTRIBITIION. NACA 64A010 AIRFOIL: $M=0.80$; $a_{m}=-0.19 ; \operatorname{Re}=12.56 \times 10^{6}$.

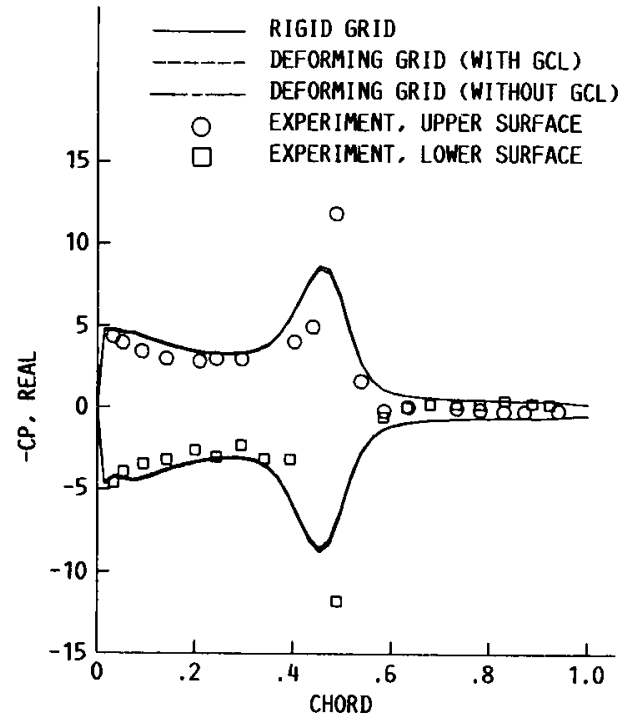

FIGURE 8. - REAL COMPONENT, FIRST HARMONIC OF PRESSURE DISTRIBUTION. NACA 64A010 AIRFOIL: $M=0.80 ; a_{m}=-0.19: a_{1}=$ $\pm 1.02 ; k=0.202 ; \operatorname{Re}=12.56 \times 10^{6}$.

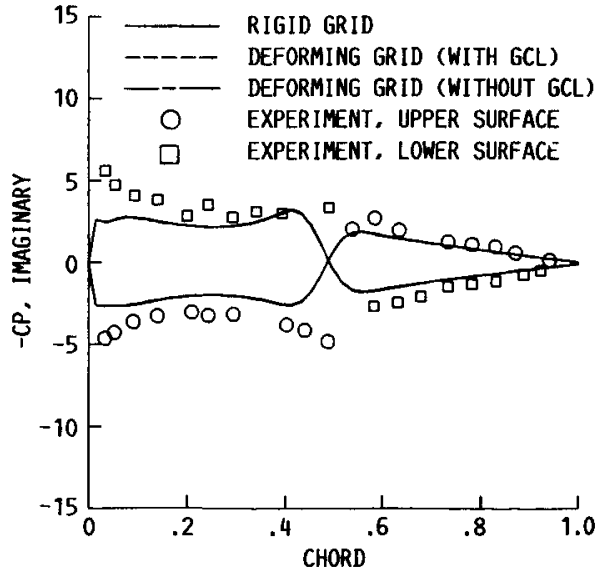

FIGURE 9. - IMAGINARY COMPONENT, FIRST HARMONIC OF PRESSURE DISTRIBUTION. NACA 64A010 AIRFOIL; $M=0.80 ; \alpha_{m}=-0.19$ : $a_{1}= \pm 1.02 ; k=0.202 ; \operatorname{Re}=12.56 \times 10^{6}$.

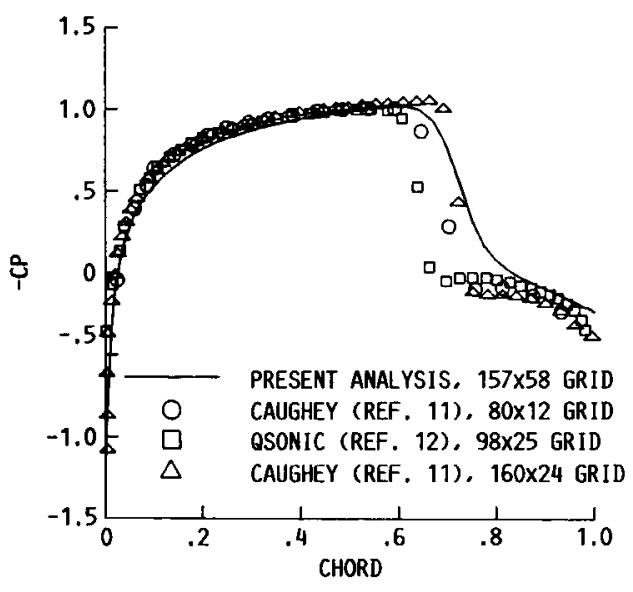

FIGURE 10. - PRESSURE DISTRIBUTION. NACA 0012 CASCADE: $g=3.6 ; M=0.80 ; a=0$. 


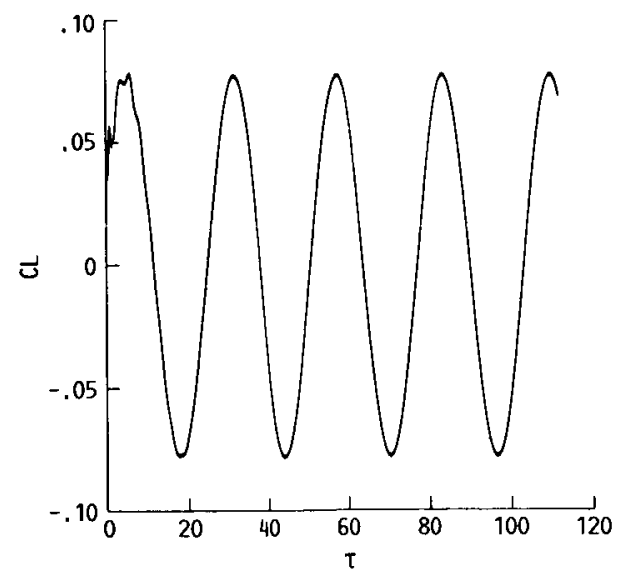

FIGURE 11. - CL VERSUS TIME. NACA 0012 CASCADE: $M=0.593 ; g=1.0: a_{m}=0: a_{1}=$ $\pm 2.0: k=0.20 ; \operatorname{Re}=3.21 \times 10^{6}$.

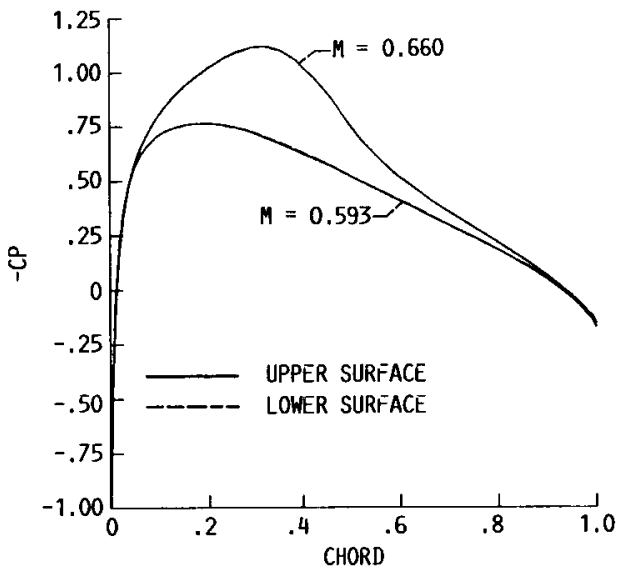

FIGURE 13. - MEAN PRESSURE DISTRIBUTION. NACA 0012 CASCADE; $g=1.0 ; a=0$; $\operatorname{Re}=3.21 \times 10^{6}$

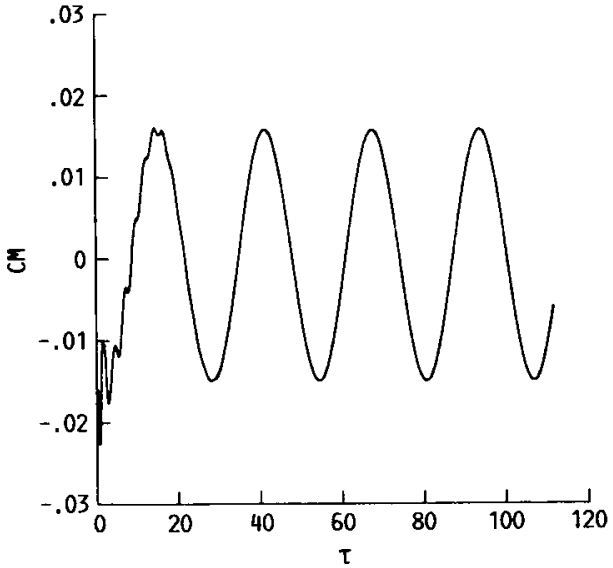

FIGURE 12. - CM VERSUS TIME. NACA 0012 CASCADE: $M=0.593 ; g=1.0 ; a_{m}=0$; $a_{1}= \pm 2.0 ; k=0.20 ; \operatorname{Re}=3.21 \times 10^{6}$.

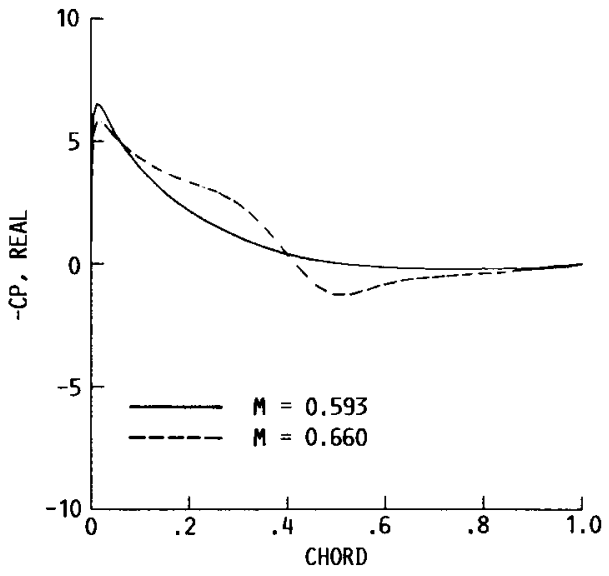

FIGURE 14. - REAL COMPONENT, FIRST HARMONIC OF PRESSURE DISTRIBUTION ON UPPER SURFACE NACA 0012 CASCADE: $g=1.0 ; a_{m}=0: a_{1}=$ $\pm 2.0: k=0.20: \operatorname{Re}=3.21 \times 10^{6}$.

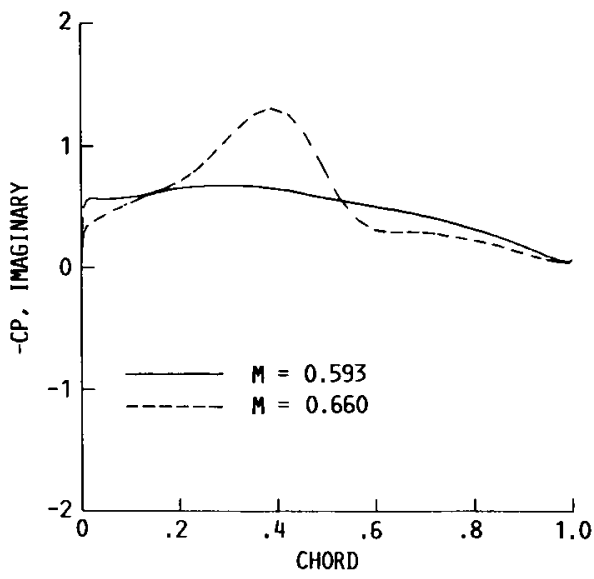

FIGURE 15. - IMAGINARY COMPONENT, FIRST HARMONIC OF PRESSURE DISTRIBUTION ON UPPER SURFACE. NACA 0012 CASCADE:

$g=1.0 ; a_{m}=0: a_{1}= \pm 2.0:$

$k=0.20: \operatorname{Re}=3.21 \times 10^{6}$. 


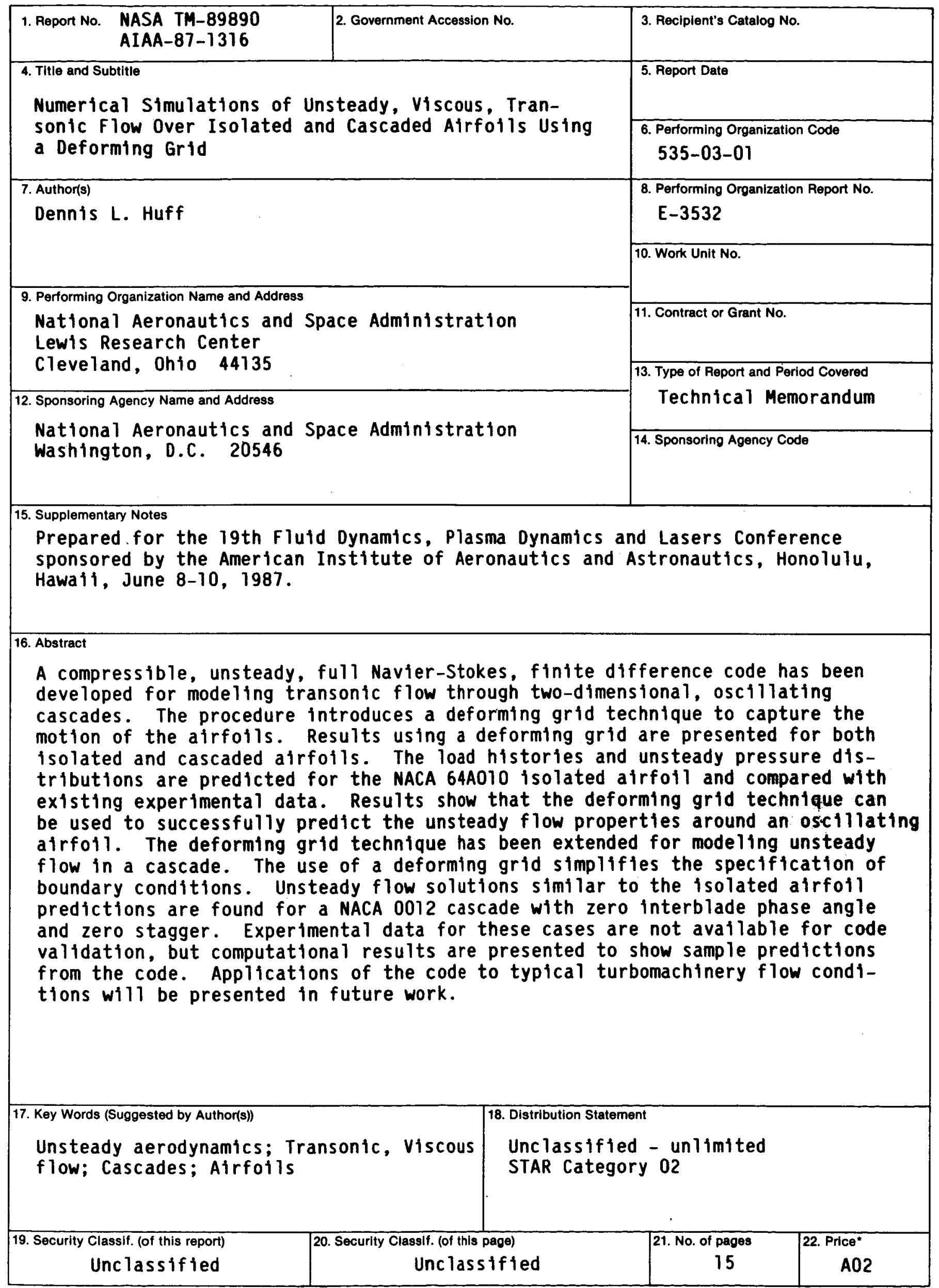

"For sale by the National Technical Information Service, Springfield, Virginia 22161 